\title{
FOLH1 Positive
}

National Cancer Institute

\section{Source}

National Cancer Institute. FOLH1 Positive. NCI Thesaurus. Code C153464.

An indication that FOLH1 expression has been detected in a sample. 